\title{
Week one FLT-PET response predicts complete remission to R-CHOP and survival in DLBCL
}

\author{
Ken Herrmann ${ }^{1,2, *}$, Andreas K. Buck ${ }^{1,2, *}{ }^{,}$Tibor Schuster $^{3}$, Kathrin Abbrederis ${ }^{4}$, \\ Christina Blümel ${ }^{2}$, Ivan Santi ${ }^{1}$, Martina Rudelius ${ }^{5,6}$, Hans-Jürgen Wester ${ }^{1}$, Christian \\ Peschel $^{4}$, Markus Schwaiger ${ }^{1}$, Tobias Dechow ${ }^{4,7}$ and Ulrich Keller ${ }^{4}$ \\ ${ }^{1}$ Department of Nuclear Medicine, Technische Universität München, Munich, Germany \\ 2 Department of Nuclear Medicine, Universitätsklinikum Würzburg, Würzburg, Germany \\ ${ }^{3}$ Department of Epidemiology, Biostatistics and Occupational Health, McGill University, Montreal, Canada \\ ${ }^{4}$ III. Medical Department, Technische Universität München, Munich, Germany \\ ${ }^{5}$ Institute of Pathology, Technische Universität München, Munich, Germany \\ ${ }^{6}$ Institute of Pathology, Universitätsklinikum Würzburg, Würzburg, Germany \\ 7 Oncology Ravensburg, Ravensburg, Germany \\ * These Authors contributed equally to this work \\ Correspondence to: Ulrich Keller, email: ulrich.keller@Irz.tum.de
}

Ken Herrmann, email: Herrmann_Kl@ukw.de

Keywords: Lymphoma; DLBCL; Positron emission tomography; [18F]Fluorodeoxythymidine; FLT-PET

Received: March 28, $2014 \quad$ Accepted: May 17, $2014 \quad$ Published: May 19, 2014

This is an open-access article distributed under the terms of the Creative Commons Attribution License, which permits unrestricted use, distribution, and reproduction in any medium, provided the original author and source are credited.

\section{ABSTRACT}

Despite improved survival in the Rituximab $(R)$ era, a considerable number of patients with diffuse large B-cell lymphoma (DLBCL) ultimately die from the disease. Functional imaging using $\left[{ }^{18} \mathrm{~F}\right]$ fluorodeoxyglucose-PET is suggested for assessment of residual viable tumor very early during treatment but is compromised by non-specific tracer retention in inflammatory lesions. The PET tracer $\left.{ }^{[18} \mathrm{F}\right]$ fluorodeoxythymidine (FLT) as surrogate marker of tumor proliferation may overcome this limitation. We present results of a prospective clinical study testing FLT-PET as superior and early predictor of response to chemotherapy and outcome in DLBCL. 54 patients underwent FLT-PET prior to and one week after the start of R-CHOP chemotherapy. Repetitive FLT-PET imaging was readily implemented into the diagnostic work-up. Our data demonstrate that the reduction of FLT standard uptake value ${ }_{\text {mean }}\left(\right.$ SUV $\left._{\text {mean }}\right)$ and SUV max $_{\text {max }}$ one week after chemotherapy was significantly higher in patients achieving complete response $(C R, n=48 ;$ non- $C R, n=6 ; p<0.006)$. Martingale-residual and Cox proportional hazard analyses showed a significant monotonous decrease of mortality risk with increasing change in SUV. Consistent with these results, early FLT-PET response showed relevant discriminative ability in predicting CR. In conclusion, very early FLTPET in the course of R-CHOP chemotherapy is feasible and enables identification of patients at risk for treatment failure.

\section{INTRODUCTION}

CHOP (cyclophosphamide, doxorubicine, vincristine and prednisone) or CHOP-like chemotherapy in combination with the chimeric monoclonal anti-CD20 antibody rituximab $(\mathrm{R})$ is the standard of care in diffuse large B-cell lymphoma (DLBCL). Despite improved overall response rates and progression free (PFS) as well as overall survival (OS) in the R era, a considerable fraction of patients does not achieve a durable remission after first line treatment and will ultimately die from the disease. Therefore, it remains crucial to identify these patients prior to or early in the course of treatment [1-3].

DLBCL is heterogeneous with respect to biology 
and clinical course. The international prognostic index (IPI) allows estimation of the individual prognosis based on easily available parameters [4] and has remained useful for risk estimation in the rituximab era [5]. Important insights into the molecular biology of this entity have been gained with the introduction of DNA microarrays, which provide a genome-wide profile of mRNA expression levels in cancer samples. Gene expression profiling (GEP) studies support the view that DLBCL is a heterogeneous diagnostic category, as 3 molecular subtypes, termed germinal center B-cell (GCB) DLBCL, activated B-cell (ABC) DLBCL, and primary mediastinal B-cell lymphoma (PMBL), could be detected, which are often indistinguishable using conventional diagnostic tools. These diagnostic DLBCL categories have significantly different survival rates after standard treatment [6-9].

A different attempt to identify patients with higher risk of treatment failure is to perform functional PET imaging. However, while interim FDG-PET has proven useful to identify patients that have an excellent prognosis after standard treatment, this modality has heretofore failed to accurately identify patients who would benefit from alternative treatment strategies or who should be included into clinical trials due to dismal outcome with R-CHOP-like therapy [10-13]. An earlier identification of patients using an alternative radiotracer that allows response assessment immediately after initiation of chemotherapy may be beneficial. A promising candidate is the thymidine analog $3^{\prime}$-deoxy-3 $-\left[{ }^{18} \mathrm{~F}\right]$ fluorothymidine (FLT), a PET tracer derived from the cytostatic drug azidovudine (AZT), that allows in vivo imaging of proliferating tissues and malignant tumors [14]. Recently, published studies demonstrated a significant correlation of tumor cell proliferation and FLT uptake in lymphoma and solid tumors [15-21]. Recent studies have also shown that FLT-PET allows non-invasive assessment of tumor grading, very early response assessment, and possibly survival $[15,19,22-24]$ in experimental animal models and patients.

Predictive markers are desirable for guiding risk-adjusted treatment in lymphoma. The aim of this prospective study was to assess the suitability of FLT and in particular the decrement of FLT uptake one week after start of immuno-chemotherapy to predict response and clinical outcome in patients with DLBCL.

\section{RESULTS}

\section{Response to therapy and survival}

54 patients met the inclusion criteria and completed the full protocol. Staging was performed according to established standards using CT/PET-CT scans as the reference method. Results are shown in Table 1. End of therapy assessment was available in 52 patients and indicated $\mathrm{CR}$ in 46 patients, $\mathrm{PR}$ in 2 patients, and $\mathrm{PD}$ was found in 4 patients, respectively. Importantly, FDGpositivity was found in 5 of the 32 patients with end of treatment FDG-PET, including 4 patients in the non-CR group. Two patients were lost to follow-up. Recurrence and death were reported in $6(11 \%)$ and $7(13 \%)$ patients respectively. The estimated 1-, 3- and 5-year recurrence free survival probabilities ( $95 \%$ confidence interval) were 0.94 ( 0.89 to $>0.99), 0.90$ (0.81 to 0.99$)$ and 0.78 $(0.59$ to $>0.99)$. The respective estimated overall survival probabilities were 0.94 ( 0.89 to $>0.99), 0.89$ ( 0.80 to 0.99 ) and 0.76 (0.59 to 0.97$)$ (Fig. 1).

\section{FLT uptake reduction one week after chemotherapy}

Mean uptake of FLT-1 in lymphoma manifestations (mean FLT-1 SUV) was 7.3 (range 1.0 - 18.2). Corresponding maximum FLT-1 uptake values ranged from $1.2-20.4$, resulting in a mean of FLT-1 SUV max $_{\max }$ of 9.3. Mean $\mathrm{SUV}_{\text {mean }}$ decreased one week after start of treatment (FLT-2) to 1.8 (range $0.3-7.4$ ) (Table 2), resulting in a mean decrease of $73.1 \%$ (range: $0.0 \%$ $95.8 \%$ ) (Table 2). Corresponding $\mathrm{SUV}_{\text {max }}$ values of FLT2 PET were 2.4 (range: $0.4-9.6$ ) calculating to a mean decrease of $73.6 \%$ (range: $10.8 \%-96.1 \%$ ) for change of $\mathrm{SUV}_{\text {max }}$ (Table 2,). Thus, FLT PET performed one week after standard treatment results in a substantial decrease in both mean and maximal tracer uptake.

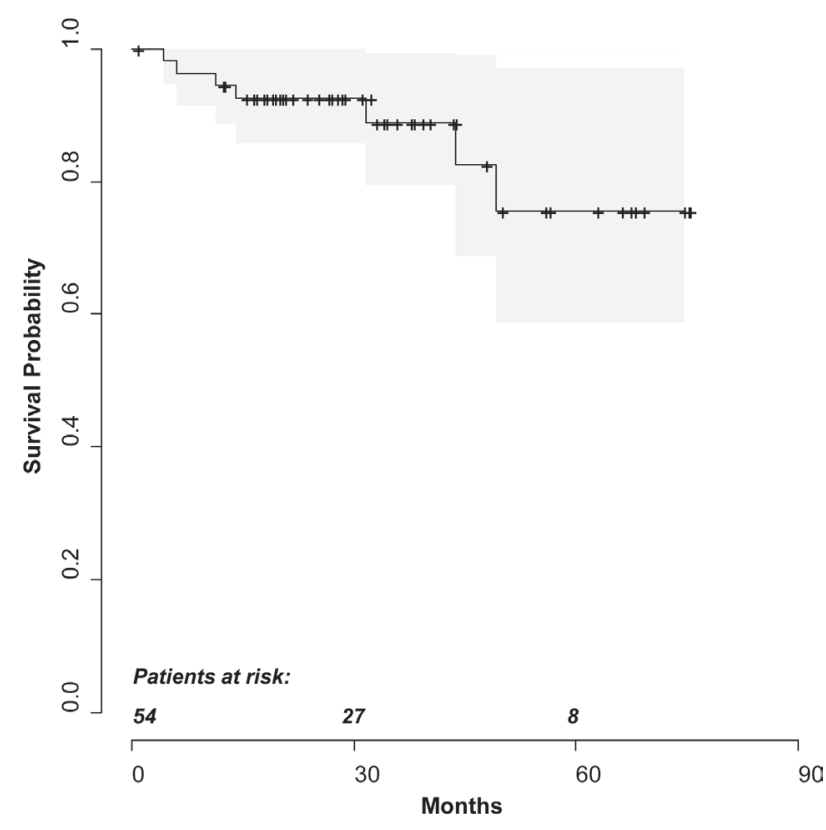

Figure 1: Kaplan-Meier curve depicting estimated overall survival probabilities. Shaded area indicates the $95 \%$ confidence interval for the survival function. Observation times of individuals without fatal event (censored cases) are marked with the symbol + . 
Table 1: Patient characteristics.

\begin{tabular}{|c|c|c|}
\hline Characteristic & Number & Percentage \\
\hline $\begin{array}{l}\text { Age } \\
\text { Median } \\
\text { Range }\end{array}$ & $\begin{array}{c}62.5 \\
(26-80)\end{array}$ & \\
\hline $\begin{array}{l}\text { Histology } \\
\qquad \begin{array}{l}\text { DLBCL } \\
\text { FL grade IIIB }\end{array}\end{array}$ & $\begin{array}{c}52 \\
2\end{array}$ & $\begin{array}{c}96 \\
4\end{array}$ \\
\hline $\begin{array}{l}\text { IPI score } \\
\qquad \begin{array}{l}0 / 1 \\
2 \\
3 \\
4 / 5\end{array}\end{array}$ & $\begin{array}{c}22 \\
12 \\
12 \\
8\end{array}$ & $\begin{array}{l}40 \\
23 \\
23 \\
14\end{array}$ \\
\hline $\begin{array}{l}\text { Stage } \\
\qquad \begin{array}{l}\text { I } \\
\text { II } \\
\text { III } \\
\text { IV }\end{array}\end{array}$ & $\begin{array}{c}14 \\
7 \\
5 \\
28\end{array}$ & $\begin{array}{l}26 \\
13 \\
10 \\
51\end{array}$ \\
\hline
\end{tabular}

\section{FLT-2 SUV ${ }_{\text {mean } / \text { max }}$ predict achieving a CR}

Next, the FLT-2 data was analyzed for the predictive value of FLT-2 with regard to achieving a CR. Due to the low number of patients with PR or PD, FLT uptake parameters were compared for patients in CR $(n=48)$ and patients in non-CR $(\mathrm{n}=6)$. FLT-2 uptake values one week after treatment initiation were significantly lower in patients achieving a $\mathrm{CR}$ compared to non-CR patients (mean $\mathrm{SUV}_{\text {mean }}: \mathrm{P}=0.006$; mean $\mathrm{SUV}_{\text {max }}: \mathrm{P}=0.005$, Table 3 ), the patient group that contained 4 patients with a positive FDG-PET at end of treatment. Thus, FLT uptake one week after treatment is predictive for achieving a CR.

We also calculated whether the decrement in either FLT SUV was predictive. The mean decrease of $\mathrm{SUV}_{\text {mean }}$ and $\mathrm{SUV}_{\text {max }}$ was higher in patients achieving

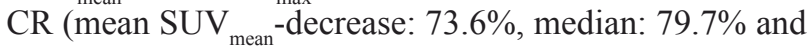

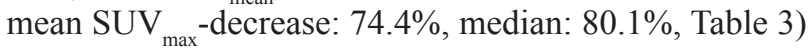
compared to non-CR patients (mean $\mathrm{SUV}_{\text {mean }}$-decrease: $65.7 \%$, median $70.5 \%$ and mean $\mathrm{SUV}_{\max }$-decrease: $63.2 \%$, median $65.5 \%$, Table 3). ROC analyses resulted in areas under the curves of 0.622 (95\%CI: $0.44-0.80)$ for SUVmean and 0.655 (95\% CI: $0.48-0.83$ ) for changes of SUVmax to predict complete response (Fig. 2). Corresponding optimal cut-offs calculated to a decrease of $79.0 \%$ SUVmean to predict a CR (positive predictive value: $92.6 \%$ ) and, respectively, $82.0 \%$ SUVmax to predict a CR (positive predictive value: $95.7 \%$ )

\section{Association of FLT uptake parameters and survival}

Six of 54 patients either progressed or relapsed after achieving a response to initial treatment and 7 patients died during the observation period (Fig. 2). Of the 7 deaths 4 were lymphoma-related (7.4\%). Martingale-residual analysis was performed for all seven death events and revealed a significant correlation between survival and change of SUV (Fig. 3). The corresponding estimated hazard ratios per one-point increment of FLT-SUV $\mathrm{mean}_{\text {man }}$ and FLT-SUV $_{\text {max }}$ were 0.65 (95\% CI: 0.50 to $0.84, \mathrm{p}=0.001$ ) and 0.60 ( $95 \% \mathrm{CI}: 0.44$ to $0.83, \mathrm{p}=0.002)$ respectively.
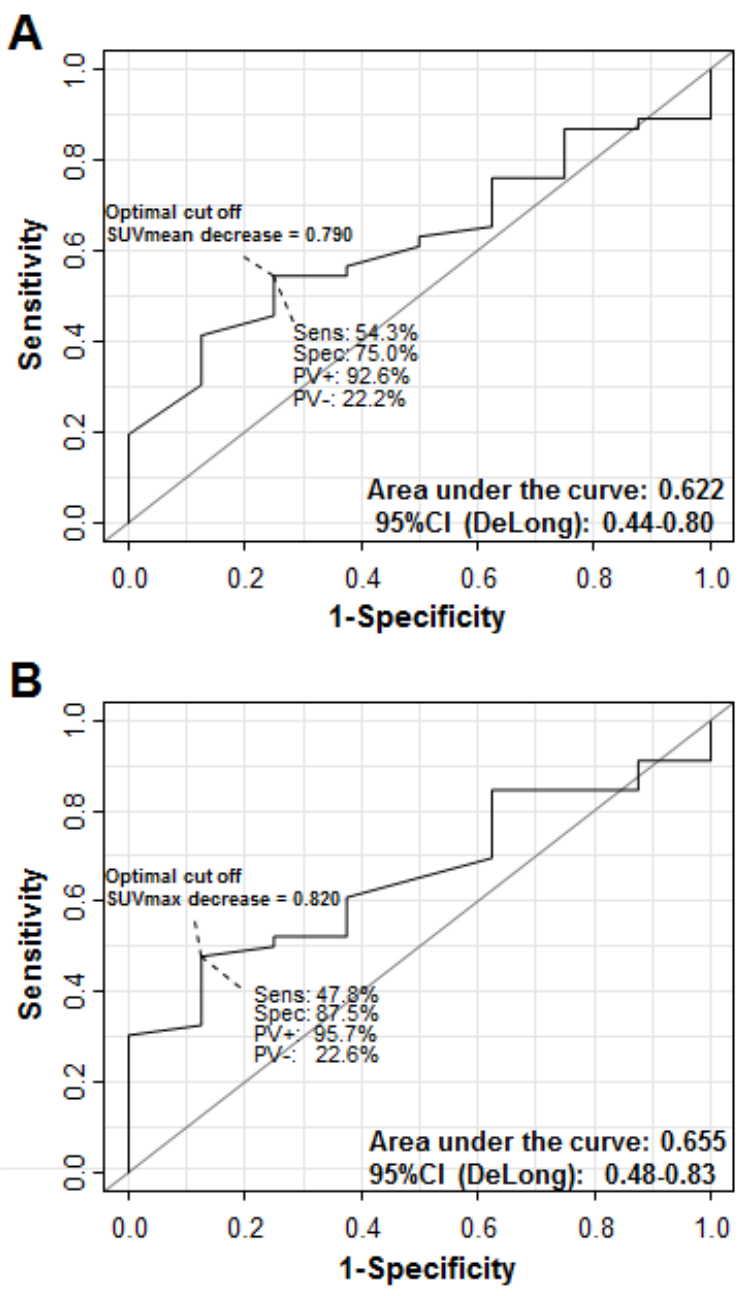

Figure 2: Diagnostic accuracy regarding prediction of complete remission using SUV decrease. A, SUVmean decrease. B, SUVmax decrease. Sens: sensitivity; Spec: specificity; $\mathrm{PV}+$ : Positive predictive value; PV-: negative predictive value; CI: confidence interval. 
Table 2: FLT-1 and FLT-2 parameters. FLT-1: represents the FLT parameters before treatment. FLT-2: represents the FLT parameters one week after treatment initiation. $\triangle \mathrm{SUV}$ : represents the change of SUV measured in FLT-1 to FLT-2 ( $\triangle \mathrm{SUV}=100$ - [SUV FLT-1 - SUV FLT2] x 100).

\begin{tabular}{|l|l|l|l|l|}
\hline Parameter & Mean & Median & Minimum & Maximum \\
\hline $\begin{array}{l}\text { SUVmean } \\
\text { FLT-1 }\end{array}$ & 7.3 & 7.0 & 1.0 & 18.2 \\
\hline $\begin{array}{l}\text { SUVmax FLT- } \\
1\end{array}$ & 9.3 & 9.0 & 1.2 & 20.4 \\
\hline $\begin{array}{l}\text { SUVmean } \\
\text { FLT-2 }\end{array}$ & 1.8 & 1.2 & 0.3 & 7.4 \\
\hline $\begin{array}{l}\text { SUVmax FLT- } \\
2\end{array}$ & 2.4 & 1.5 & 0.4 & 9.6 \\
\hline$\triangle$ SUVmean & 73.1 & 78.3 & 0.0 & 95.8 \\
\hline$\triangle$ SUVmax & 73.6 & 77.7 & 10.8 & 96.1 \\
\hline
\end{tabular}

\section{DISCUSSION}

The thymidine analogue FLT has been shown to reflect proliferation-dependent retention of nucleosides in malignant lymphoma, which can be assessed noninvasively by PET [25]. Several studies testing interim FDG-PET after 2-4 cycles of therapy have heretofore failed to identify patients who would benefit from alternative treatment strategies or who should be included into clinical trials due to dismal outcome with R-CHOPlike therapy [10-13]. Here we used very early interim FLT-PET performed one week after treatment initiation to test the hypothesis that, firstly, the drop in proliferation measured by FLT uptake/ retention and, secondly, the remaining FLT uptake (FLT-2 SUV) may allow predicting not only treatment response but also survival.

In concordance with the recent report of Lee and colleagues [24] our similarly designed study (FLT-PET day 7 after cycle 1 vs. before cycle 2) that included a comparable number of patient also points to early FLTPET assessment as a prognostic/ predictive factor with regard to response and survival. Assuming that very early FLT-PET assessment should reflect immediate treatment efficacy we deliberately chose this very short interval between treatment initiation and second FLT-PET imaging. Concluding from the comparison of these two studies however the very early assessment performed at day 7 might be too early and therefore inferior. It is possible that the use of immunotherapy may increase

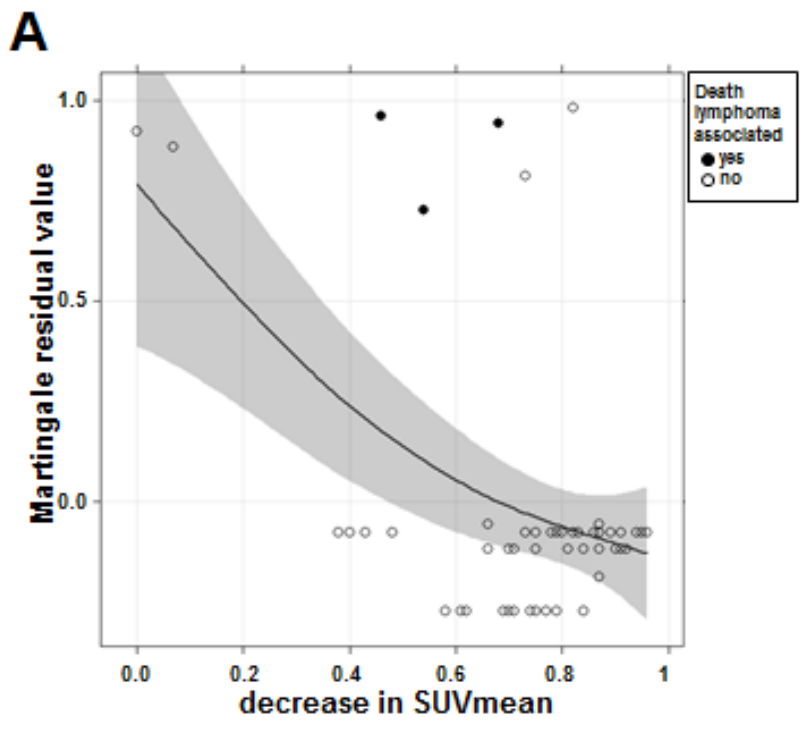

$$
\begin{aligned}
& \text { Average risk reduction per each } 0.1 \text { point } \\
& \text { decrease in } \mathrm{FLT} \text {-SUV } \text { mean } \mathrm{HR}=0.65 \\
& (95 \% \mathrm{Cl}: 0.50 \text { to } 0.84, \mathrm{P}=0.001)
\end{aligned}
$$

B

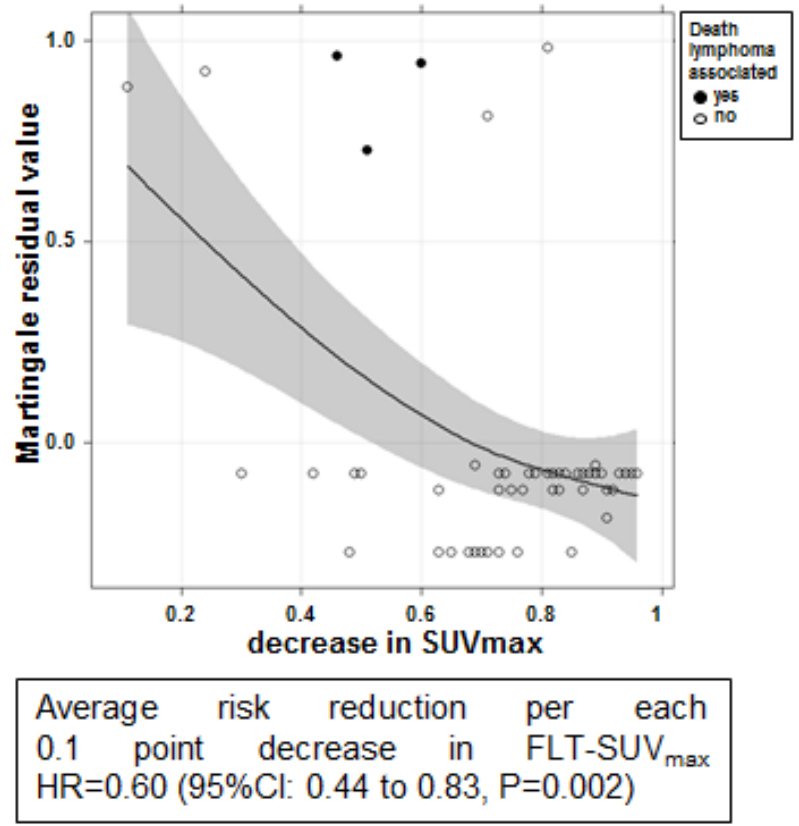

Figure 3: Martingale-residual analysis: decrease in A, SUVmean and B, SUVmax and the risk of death in patients achieving a complete remission (CR) or not (PR: partial response; PD: progressive disease). Solid lines depict smoothing functions with $95 \%$ confidence bands. Decreasing Martingale-residual values with higher decrease in SUVmean / SUVmax indicate a decline in risk of death with higher SUV decrement. 
Table 3: FLT uptake values depending on response.

\begin{tabular}{|c|c|c|c|c|c|}
\hline Parameter & Mean & Median & Minimum & Maximum & P-Value \\
\hline FLT-1 SUVmean non-CR-group & 9.3 & 8.8 & 6.2 & 13.7 & \multirow{2}{*}{0.073} \\
\hline FLT-1 SUVmean CR group & 7.2 & 7.0 & 1.0 & 18.2 & \\
\hline FLT-1 SUVmax non-CR-group & 10.9 & 10.6 & 7.0 & 16.4 & \multirow{2}{*}{0.265} \\
\hline FLT-1 SUVmax CR group & 9.2 & 8.8 & 1.2 & 20.4 & \\
\hline FLT-2 SUVmean non-CR-group & 3.4 & 2.2 & 1.9 & 7.4 & \multirow{2}{*}{0.006} \\
\hline FLT-2 SUVmean CR group & 1.7 & 1.1 & 0.3 & 7.4 & \\
\hline FLT-2 SUVmax non-CR-group & 4.2 & 2.8 & 2.4 & 8.9 & \multirow{2}{*}{0.005} \\
\hline FLT-2 SUVmax CR group & 2.2 & 1.4 & 0.4 & 9.6 & \\
\hline Decrease SUVmean non-CR-group & 65.7 & 70.5 & 46.0 & 78.1 & \multirow{2}{*}{0.089} \\
\hline Decrease SUVmean CR group & 73.6 & 79.7 & 0.0 & 95.8 & \\
\hline Decrease SUVmax non-CR-group & 63.2 & 65.5 & 45.7 & 78.0 & \multirow{2}{*}{0.064} \\
\hline Decrease SUVmax CR group & 74.4 & 80.1 & 10.8 & 96.1 & \\
\hline
\end{tabular}

lesion inflammation. Since the mode of supposed action for rituximab involves, next to direct pro-apoptotic or complement-mediated effects [26] also antibodydependent cellular cytotoxicity via the $\mathrm{Fc}$ fragment of the antibody [27], the interval selected in our study could be too short to optimally assess treatment efficacy. Similarly, FDG measurement requires a minimum interval to immuno-chemotherapy due to a transient increase in stromal reaction that may result in overestimation of the fraction of viable cells [28]. The recommendations by the European Organization for Research and Treatment of Cancer consider a time interval of one to two weeks between completion of a chemotherapy cycle and FDG PET optimal to avoid transient flare at the disease sites [29]. Thus a certain delay may be more suitable for FLT-PET, too. On the other hand our study clearly demonstrates in a large cohort that the decrement in FLT uptake briefly after one therapy cycle is quite substantial.

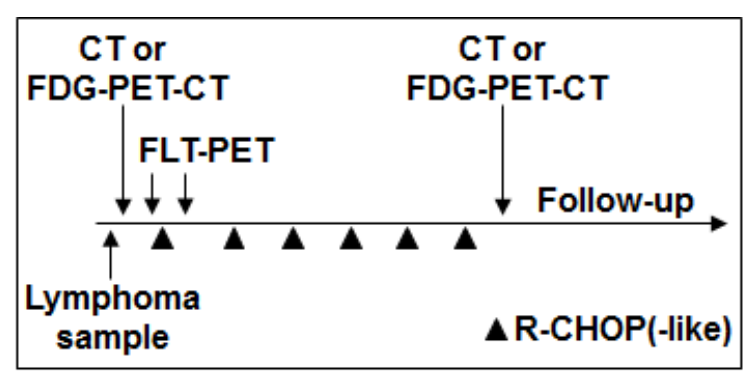

Figure 4: PET imaging and treatment schedule
We define an optimal cut-off value for SUVmean (79\%) and SUVmax (82\%) decrease predictive for achieving a complete remission, an important prognostic factor in first line treatment of DLBCL [30].

Besides the above discussed limitations of our study regarding the very early time point of assessment, the moderate power to predict survival is however clearly limited by the bias towards a patient cohort not under immediate treatment pressure. Although synthesis is highly standardized, FLT remains an experimental PET tracer and was therefore only available once a week at our institution. This limitation did not allow us to include more patients with adverse prognostic factors, and reduced performance status due to lymphoma activity is a very important adverse prognostic factor [4]. Including patients selected for adverse prognostic factors determined for example by IPI score $(4,5)$, molecular assessment (31-33) or also by advanced not yet broadly available techniques (34-37) should allow to define a high risk population more exactly than one single approach alone. Such a high risk patient selection would also come by assessing the suitability of FLT for early prediction of treatment failure in a refractory/relapsed patient cohort [38].

To our knowledge we present results of one of only two prospective studies investigating the predictive value of very early interim FLT-PET regarding response to treatment and survival in aggressive B-NHL. Despite the favourable prognosis and outcome of patients in our series, a significant role of FLT-PET for early survival prediction could be demonstrated. However, although 
the study results suggest potential usefulness of FLT-PET for response prediction (upper confidence limits of the estimated discrimination indices $>0.8$ ), further studies need to be conducted to establish optimal thresholds and to define more precisely the associated predictive performance. Several adjustments with regard to timing and patient selection in upcoming trials investigating FLT or other novel PET tracers will be required.

\section{METHODS}

\section{Patients}

54 patients with biopsy proven aggressive B-cell Non-Hodgkin lymphoma (B-NHL) were included in this prospective study and completed the full FLT-PET imaging protocol (26 men, 28 women, mean age: $58 \pm 15$ years). All patients were scheduled to undergo systemic chemotherapy with R-CHOP-like treatment. Detailed patient characteristics and risk factors are shown in Table 1 .

All 54 patients underwent a pre-therapeutic FLTPET scan (FLT-1) as well as second scan (FLT-2) one week after start of treatment (Fig. 4). Exclusion criteria included previous or concurrent malignancies, preceding chemo- or radiotherapy, and patients younger than 18 years. Details of the study were explained by a physician and written informed consent was obtained from all patients. The study protocol was approved by the responsible ethics committee of the Technische Universität München.

\section{Study design}

Baseline FLT-PET examination (FLT-1) was performed within 1 week before therapy, together with standard staging modalities (clinical examination, CT). As FDG-PET is not routinely reimbursed in Germany, it was available only for initial staging in a subgroup of patients $(n=32)$. FLT-PET imaging was repeated in all 54 patients around one week after the start of the first course of R-CHOP treatment (FLT-2) (range, day 5 to day 8, mean 6.3 days). An end of therapy FDG-PET as recommended by the revised response criteria published in 2007 was performed in 32 of the patients.

Patients received R-CHOP therapy in standard dose (rituximab $375 \mathrm{mg} / \mathrm{m}^{2}$, cyclophosphamide $750 \mathrm{mg} / \mathrm{m}^{2}$ day 1 , doxorubicin $50 \mathrm{mg} / \mathrm{m}^{2}$ day 1 , vincristine $1.4 \mathrm{mg} / \mathrm{m}^{2}$ day 1 and prednisone $100 \mathrm{mg}$ day $1-5$ ) every 2 or 3 weeks with dose modification or delays according to common standards. 3 patients received additional etoposide $100 \mathrm{mg} /$ $\mathrm{m}^{2}$ day 1-3 (R-CHOEP) and in one patient liposomal doxorubicin was used with $30 \mathrm{mg} / \mathrm{m}^{2}$ per day.

\section{Histopathological classification}

Histology of lymphomas was classified according to the updated WHO classification system [39]. In all 54 patients histopathology revealed aggressive B-NHL (Table 1), including 52 patients with DLBCL and 2 patients with follicular lymphoma (FL) grade 3 b.

\section{PET Imaging}

3'-deoxy-3'-[ $\left[{ }^{18} \mathrm{~F}\right]$ fluorothymidine was synthesized as previously described [40]. Imaging was performed on a whole-body high resolution PET scanner (ECAT HR+; Siemens/CTI; Knoxville, TN). This device simultaneously acquires 47 contiguous slices with a slice thickness of 3.4 $\mathrm{mm}$. The in-plane image resolution of transaxial images was approximately $8 \mathrm{~mm}$ full width at half maximum (FWHM), with an axial resolution of approximately $5 \mathrm{~mm}$ FWHM

Static emission images were acquired 45 minutes after injection of approximately $300 \mathrm{MBq}$ FLT (range: 270 - $340 \mathrm{MBq}$ ). Emission data were corrected for random coincidences, dead time and attenuation and reconstructed by filtered backprojection (Hanning filter with cut-off frequency 0.4 cycle per bin). The matrix size was $128 \mathrm{x}$ 128 pixels with a pixel size of $4.0 \times 4.0 \mathrm{~mm}$. The image pixel counts were calibrated to activity concentrations (Becquerel/milliliter) and decay corrected using the time of tracer injection as reference.

\section{PET Data Analysis}

All PET scans were evaluated by two observers (board-certified nuclear medicine specialists) blinded to the clinical data and the results of other imaging studies. Circular regions of interest (ROIs) with a diameter of 1.5 $\mathrm{cm}$ were placed in the area with the highest tumor activity, as previously published [41]. Mean lesion diameter and range of initial tumor size were $4.6 \mathrm{~cm}$ (median: 4.0, range: $2.0-17.5)$. Mean standardized uptake values (SUV) were calculated from each ROI using the formula: SUV $=$ measured activity concentration $(\mathrm{Bq} / \mathrm{g}) \mathrm{x}$ body weight (g)/injected activity (Bq). For further analyses, mean values from both observers were used. Side-by-side analysis has been performed to ensure SUV-calculation in identical ROIs at various time points. This algorithm has been demonstrated to be a valuable tool for assessment of treatment response [41, 42].

For definition of ROIs and data analysis, computer programs were developed in the Interactive Data Language (IDL; Research Systems, Inc., Boulder, Co) using the Clinical Application Programming Package (CAPP; Siemens/CTI, Inc.) [43]. 


\section{Clinical Evaluation and Follow-up}

$\mathrm{CT}$ was performed as part of the routine clinical management in all patients. Baseline CT of neck, thorax, abdomen, and pelvis were performed in all patients before chemotherapy. Patients were reevaluated by means of CT after 3 and 6 courses of chemotherapy. The treatment response was classified after completion of 6 cycles of R-CHOP/CHOP as complete response (CR), partial response (PR), no change (NC), or progressive disease (PD) according to the RECIST 1.1 criteria based on the bi-dimensional diameters of corresponding tumor lesions measured by ruler or caliper [44]. Further follow up evaluations were carried out according to standard protocols every 3 months. The median follow-up estimated by the inverse Kaplan-Meier method [45] was 32.2 months (range: 11.5 - 73.2 months; median: 28.6 months). The patient management was not influenced by the results of FLT-PET studies.

\section{Statistical Analysis}

Statistical analyses were performed using PASW Statistics software (version 20.0; SPSS, Inc. Chicago, IL) and the statistical software R [46]. Quantitative values were expressed as mean \pm standard deviation or median and range as appropriate. Comparisons of related metric measurements were performed using Wilcoxonsigned rank test and the Mann-Whitney-U test was used to compare quantitative data between two independent samples. To assess prognostic impact of continuous variables with regard to survival, Martingale-residual analysis was performed [47]. Smoothing spline equations have been fitted to the residual plots to depict shape of functional relationship between the continuous prognostic variable and the risk of death.

Fisher's exact test was used for comparison of frequencies and Spearman correlation coefficients were calculated to quantify bivariate correlations of measurement data. Exact two-sided 95 percent confidence intervals (CI) were reported for estimates of sensitivity and specificity. In order to assess the discriminative ability of FLT-SUV decreases for the dichotomous outcome tumor response (complete remission (CR) versus partial response (PR) or progressive disease (PD)), receiver operating characteristics (ROC) curves were fitted and the area under the curve (AUC) along with $95 \%$ confidence intervals reported. All statistical tests were conducted two-sided and a p-value less than 0.05 was considered to indicate statistical significance. No correction of $p$-values was considered in the course of multiple testing; however, results of all performed tests were thoroughly reported, allowing for an informal adjustment for multiplicity while reviewing the data [48].

\section{ACKNOWLEDGEMENTS}

The authors would like to thank Stephan Nekolla, Sandra van Marwick, Brigitte Dzewas and Coletta Kruschke for technical support. This work received grants from the Deutsche Forschungsgemeinschaft (SFB 824, projects $\mathrm{C} 3, \mathrm{Z} 1$ ) and the German Consortium for Translational Cancer Research (DKTK).

\section{Conflicts of interest statement:}

The authors declare that there are no conflicts of interest.

\section{REFERENCES}

1. Coiffier B, Lepage E, Briere J, Herbrecht R, Tilly H, Bouabdallah R, Morel P, Van Den Neste E, Salles G, Gaulard P, Reyes F, Lederlin P and Gisselbrecht C. CHOP chemotherapy plus rituximab compared with $\mathrm{CHOP}$ alone in elderly patients with diffuse large-B-cell lymphoma. The New England journal of medicine. 2002; 346(4):235-242.

2. Pfreundschuh M, Trumper L, Osterborg A, Pettengell R, Trneny M, Imrie K, Ma D, Gill D, Walewski J, Zinzani PL, Stahel R, Kvaloy S, Shpilberg O, Jaeger U, Hansen M, Lehtinen T, et al. CHOP-like chemotherapy plus rituximab versus $\mathrm{CHOP}$-like chemotherapy alone in young patients with good-prognosis diffuse large-B-cell lymphoma: a randomised controlled trial by the MabThera International Trial (MInT) Group. Lancet Oncol. 2006; 7(5):379-391.

3. Friedberg JW and Fisher RI. Diffuse large B-cell lymphoma. Hematology/oncology clinics of North America. 2008; 22(5):941-952, ix.

4. A predictive model for aggressive non-Hodgkin's lymphoma. The International Non-Hodgkin's Lymphoma Prognostic Factors Project. The New England journal of medicine. 1993; 329(14):987-994.

5. Ziepert M, Hasenclever D, Kuhnt E, Glass B, Schmitz N, Pfreundschuh $\mathrm{M}$ and Loeffler M. Standard International prognostic index remains a valid predictor of outcome for patients with aggressive CD20+ B-cell lymphoma in the rituximab era. Journal of clinical oncology : official journal of the American Society of Clinical Oncology. 2010; 28(14):2373-2380.

6. Nogai H, Dorken B and Lenz G. Pathogenesis of NonHodgkin's Lymphoma. Journal of Clinical Oncology. 2011; 29(14):1803-1811.

7. Alizadeh AA, Eisen MB, Davis RE, Ma C, Lossos IS, Rosenwald A, Boldrick JC, Sabet H, Tran T, Yu X, Powell JI, Yang L, Marti GE, Moore T, Hudson J, Jr., Lu L, et al. Distinct types of diffuse large B-cell lymphoma identified by gene expression profiling. Nature. 2000; 403(6769):503511.

8. Savage KJ, Monti S, Kutok JL, Cattoretti G, Neuberg D, De 
Leval L, Kurtin P, Dal Cin P, Ladd C, Feuerhake F, Aguiar RC, Li S, Salles G, Berger F, Jing W, Pinkus GS, et al. The molecular signature of mediastinal large B-cell lymphoma differs from that of other diffuse large B-cell lymphomas and shares features with classical Hodgkin lymphoma. Blood. 2003; 102(12):3871-3879.

9. Bret C, Klein B and Moreaux J. Gene expression-based risk score in diffuse large B-cell lymphoma. Oncotarget. 2012; 3(12):1700-1710.

10. Haioun C, Itti E, Rahmouni A, Brice P, Rain JD, Belhadj K, Gaulard P, Garderet L, Lepage E, Reyes F and Meignan M. [18F]fluoro-2-deoxy-D-glucose positron emission tomography (FDG-PET) in aggressive lymphoma: an early prognostic tool for predicting patient outcome. Blood. 2005; 106(4):1376-1381.

11. Moskowitz CH, Schoder H, Teruya-Feldstein J, Sima C, Iasonos A, Portlock CS, Straus D, Noy A, Palomba ML, O'Connor OA, Horwitz S, Weaver SA, Meikle JL, Filippa DA, Caravelli JF, Hamlin PA, et al. Risk-adapted dosedense immunochemotherapy determined by interim FDGPET in Advanced-stage diffuse large B-Cell lymphoma. Journal of clinical oncology : official journal of the American Society of Clinical Oncology. 28(11):1896-1903.

12. Cheson BD. Role of functional imaging in the management of lymphoma. J Clin Oncol. 2011; 29(14):1844-1854.

13. Casasnovas RO, Meignan M, Berriolo-Riedinger A, Itti E, Huglo D, Haioun C and Morschhauser F. Early interim PET scans in diffuse large B-cell lymphoma: can there be consensus about standardized reporting, and can PET scans guide therapy choices? Current hematologic malignancy reports. 2012; 7(3):193-199.

14. Shields AF, Grierson JR, Dohmen BM, Machulla HJ, Stayanoff JC, Lawhorn-Crews JM, Obradovich JE, Muzik $\mathrm{O}$ and Mangner TJ. Imaging proliferation in vivo with [F-18]FLT and positron emission tomography. Nature medicine. 1998; 4(11):1334-1336.

15. Buck AK, Bommer M, Stilgenbauer S, Juweid M, Glatting G, Schirrmeister H, Mattfeldt T, Tepsic D, Bunjes D, Mottaghy FM, Krause BJ, Neumaier B, Dohner H, Moller $\mathrm{P}$ and Reske SN. Molecular imaging of proliferation in malignant lymphoma. Cancer research. 2006; 66(22):1105511061 .

16. Buck AK, Halter G, Schirrmeister H, Kotzerke J, Wurziger I, Glatting G, Mattfeldt T, Neumaier B, Reske SN and Hetzel M. Imaging proliferation in lung tumors with PET: $18 \mathrm{~F}-\mathrm{FLT}$ versus $18 \mathrm{~F}-\mathrm{FDG}$. Journal of nuclear medicine : official publication, Society of Nuclear Medicine. 2003; 44(9):1426-1431.

17. Cobben DC, Elsinga PH, Suurmeijer AJ, Vaalburg W, Maas B, Jager PL and Hoekstra HJ. Detection and grading of soft tissue sarcomas of the extremities with (18)F-3'-fluoro-3' deoxy-L-thymidine. Clinical cancer research : an official journal of the American Association for Cancer Research. 2004; 10(5):1685-1690.

18. Eckel F, Herrmann K, Schmidt S, Hillerer C, Wieder
HA, Krause BJ, Schuster T, Langer R, Wester HJ, Schmid RM, Schwaiger $M$ and Buck AK. Imaging of proliferation in hepatocellular carcinoma with the in vivo marker $18 \mathrm{~F}$-fluorothymidine. Journal of nuclear medicine : official publication, Society of Nuclear Medicine. 2009; 50(9):1441-1447.

19. Herrmann K, Wieder HA, Buck AK, Schoffel M, Krause BJ, Fend F, Schuster T, Meyer zum Buschenfelde C, Wester HJ, Duyster J, Peschel C, Schwaiger M and Dechow T. Early response assessment using $3^{6}$-deoxy-3'-[18F] fluorothymidine-positron emission tomography in highgrade non-Hodgkin's lymphoma. Clinical cancer research : an official journal of the American Association for Cancer Research. 2007; 13(12):3552-3558.

20. Kenny LM, Vigushin DM, Al-Nahhas A, Osman S, Luthra SK, Shousha S, Coombes RC and Aboagye EO. Quantification of cellular proliferation in tumor and normal tissues of patients with breast cancer by [18F] fluorothymidine-positron emission tomography imaging: evaluation of analytical methods. Cancer research. 2005; 65(21):10104-10112.

21. Pio BS, Park CK, Pietras R, Hsueh WA, Satyamurthy N, Pegram MD, Czernin J, Phelps ME and Silverman DH. Usefulness of 3'-[F-18]fluoro-3'-deoxythymidine with positron emission tomography in predicting breast cancer response to therapy. Molecular imaging and biology : MIB : the official publication of the Academy of Molecular Imaging. 2006; 8(1):36-42.

22. Li Z, Graf N, Herrmann K, Junger A, Aichler M, Feuchtinger A, Baumgart A, Walch A, Peschel C, Schwaiger M, Buck A, Keller U and Dechow T. FLT-PET is superior to FDG-PET for very early response prediction in NPM-ALK-positive lymphoma treated with targeted therapy. Cancer research. 2012; 72(19):5014-5024.

23. Graf N, Herrmann K, Numberger B, Zwisler D, Aichler M, Feuchtinger A, Schuster T, Wester HJ, SenekowitschSchmidtke R, Peschel C, Schwaiger M, Keller U, Dechow $\mathrm{T}$ and Buck AK. [18F]FLT is superior to [18F]FDG for predicting early response to antiproliferative treatment in high-grade lymphoma in a dose-dependent manner. European journal of nuclear medicine and molecular imaging. 2013; 40(1):34-43.

24. Lee H, Kim SK, Kim YI, Kim TS, Kang SH, Park WS, Yun $\mathrm{T}$ and Eom HS. Early Determination of Prognosis by Interim 3'-Deoxy-3'-18F-Fluorothymidine PET in Patients with Non-Hodgkin Lymphoma. Journal of nuclear medicine : official publication, Society of Nuclear Medicine. 2013.

25. Wagner M, Seitz U, Buck A, Neumaier B, Schultheiss S, Bangerter M, Bommer M, Leithauser F, Wawra E, Munzert G and Reske SN. 3'-[18F]fluoro-3'-deoxythymidine ([18F]FLT) as positron emission tomography tracer for imaging proliferation in a murine B-Cell lymphoma model and in the human disease. Cancer research. 2003; 63(10):2681-2687.

26. Bellosillo B, Villamor N, Lopez-Guillermo A, Marce S, Esteve J, Campo E, Colomer D and Montserrat E. 
Complement-mediated cell death induced by rituximab in B-cell lymphoproliferative disorders is mediated in vitro by a caspase-independent mechanism involving the generation of reactive oxygen species. Blood. 2001; 98(9):2771-2777.

27. Johnson $\mathrm{P}$ and Glennie $\mathrm{M}$. The mechanisms of action of rituximab in the elimination of tumor cells. Semin Oncol. 2003; 30(1 Suppl 2):3-8.

28. Spaepen K, Stroobants S, Dupont P, Bormans G, Balzarini J, Verhoef G, Mortelmans L, Vandenberghe P and De WolfPeeters C. [(18)F]FDG PET monitoring of tumour response to chemotherapy: does [(18)F]FDG uptake correlate with the viable tumour cell fraction? European journal of nuclear medicine and molecular imaging. 2003; 30(5):682-688.

29. Young H, Baum R, Cremerius U, Herholz K, Hoekstra O, Lammertsma AA, Pruim J and Price P. Measurement of clinical and subclinical tumour response using [18F]fluorodeoxyglucose and positron emission tomography: review and 1999 EORTC recommendations. European Organization for Research and Treatment of Cancer (EORTC) PET Study Group. European journal of cancer. 1999; 35(13):1773-1782.

30. de Wit M, Bumann D, Beyer W, Herbst K, Clausen M and Hossfeld DK. Whole-body positron emission tomography (PET) for diagnosis of residual mass in patients with lymphoma. Annals of oncology : official journal of the European Society for Medical Oncology / ESMO. 1997; 8 Suppl 1:57-60.

31. Lenz G, Wright G, Dave SS, Xiao W, Powell J, Zhao H, $\mathrm{Xu}$ W, Tan B, Goldschmidt N, Iqbal J, Vose J, Bast M, Fu K, Weisenburger DD, Greiner TC, Armitage JO, et al. Stromal gene signatures in large-B-cell lymphomas. The New England journal of medicine. 2008; 359(22):23132323.

32. Friedberg JW. New strategies in diffuse large B-cell lymphoma: translating findings from gene expression analyses into clinical practice. Clinical cancer research : an official journal of the American Association for Cancer Research. 2011; 17(19):6112-6117.

33. Sweetenham JW. Molecular signatures in the diagnosis and management of diffuse large B-cell lymphoma. Current Opinion in Hematology. 2011; 18(4):288-292.

34. Zhang J, Grubor V, Love CL, Banerjee A, Richards KL, Mieczkowski PA, Dunphy C, Choi W, Au WY, Srivastava G, Lugar PL, Rizzieri DA, Lagoo AS, Bernal-Mizrachi L, Mann KP, Flowers C, et al. Genetic heterogeneity of diffuse large B-cell lymphoma. Proceedings of the National Academy of Sciences of the United States of America. 2013; 110(4):1398-1403.

35. Schneider C, Pasqualucci L and Dalla-Favera R. Molecular pathogenesis of diffuse large B-cell lymphoma. Seminars in diagnostic pathology. 2011; 28(2):167-177.

36. Pasqualucci L, Trifonov V, Fabbri G, Ma J, Rossi D, Chiarenza A, Wells VA, Grunn A, Messina M, Elliot O, Chan J, Bhagat G, Chadburn A, Gaidano G, Mullighan CG, Rabadan R, et al. Analysis of the coding genome of diffuse large B-cell lymphoma. Nature genetics. 2011; 43(9):830837.

37. Khodabakhshi AH, Morin RD, Fejes AP, Mungall AJ, Mungall KL, Bolger-Munro M, Johnson NA, Connors JM, Gascoyne RD, Marra MA, Birol I and Jones SJ. Recurrent targets of aberrant somatic hypermutation in lymphoma. Oncotarget. 2012; 3(11):1308-1319.

38. Gisselbrecht C, Glass B, Mounier N, Singh Gill D, Linch DC, Trneny M, Bosly A, Ketterer N, Shpilberg O, Hagberg H, Ma D, Briere J, Moskowitz CH and Schmitz N. Salvage regimens with autologous transplantation for relapsed large B-cell lymphoma in the rituximab era. Journal of clinical oncology : official journal of the American Society of Clinical Oncology. 2010; 28(27):4184-4190.

39. Jaffe ES, Harris NL, Stein H and Vardiman JH. (2001). World Health Organization Classification of Tumors. Pathology and Genetics. Tumors of Haematopoietic and lymphoid tissues.

40. Machulla HJ, Blocher A, Kuntzsch M, Piert M, Wei R and Grierson J. Simplified Labeling Approach for Synthesizing 3 prime-Deoxy-3prime-[18F]fluorothymidine ([18F]FLT). Journal of Radioanalytical and Nuclear Chemistry. 2000; 243(3):4.

41. Weber WA, Ott K, Becker K, Dittler HJ, Helmberger H, Avril NE, Meisetschlager G, Busch R, Siewert JR, Schwaiger $M$ and Fink U. Prediction of response to preoperative chemotherapy in adenocarcinomas of the esophagogastric junction by metabolic imaging. Journal of clinical oncology : official journal of the American Society of Clinical Oncology. 2001; 19(12):3058-3065.

42. Wieder HA, Brucher BL, Zimmermann F, Becker K, Lordick F, Beer A, Schwaiger M, Fink U, Siewert JR, Stein HJ and Weber WA. Time course of tumor metabolic activity during chemoradiotherapy of esophageal squamous cell carcinoma and response to treatment. J Clin Oncol. 2004; 22(5):900-908.

43. Weber WA, Ziegler SI, Thodtmann R, Hanauske AR and Schwaiger M. Reproducibility of metabolic measurements in malignant tumors using FDG PET. Journal of nuclear medicine : official publication, Society of Nuclear Medicine. 1999; 40(11):1771-1777.

44. Eisenhauer EA, Therasse P, Bogaerts J, Schwartz LH, Sargent D, Ford R, Dancey J, Arbuck S, Gwyther S, Mooney M, Rubinstein L, Shankar L, Dodd L, Kaplan R, Lacombe D and Verweij J. New response evaluation criteria in solid tumours: revised RECIST guideline (version 1.1). Eur J Cancer. 2009; 45(2):228-247.

45. Schemper M and Smith TL. A note on quantifying followup in studies of failure time. Control Clin Trials. 1996; 17(4):343-346.

46. Team RDC. (2012). A language and environment for statistical computing. (Vienna, Austria: R Foundation for Statistical Computing.).

47. Therneau TM, Grambsch PM and Fleming TR. Martingale- 
based residuals for survival models. Biometrika. 1990; 1(77):147-160.

48. Saville DJ. Multiple Comparison Procedures - the Practical Solution. Am Stat. 1990; 44(2):174-180. 